\title{
Users' attitudes towards personal health records
}

\section{A cross-sectional pilot study}

Peyman Azad Khaneghah1; Antonio Miguel-Cruz 1,3; Pamela Bentley²; Lili Liu1; Eleni Stroulia4; Martin Ferguson-Pell²

${ }^{1}$ Department of Occupational Therapy, University of Alberta, Edmonton, Canada;

${ }^{2}$ Faculty of Rehabilitation Medicine, University of Alberta, Edmonton, Canada;

${ }^{3}$ School of Medicine and Health Sciences, Universidad del Rosario, Bogota, Colombia;

${ }^{4}$ Department of Computing Science, Faculty of Science, University of Alberta, Edmonton, Canada

\section{Keywords}

Chronic disease, diabetes mellitus, personal health records

\section{Summary}

Background: Prevention and management of chronic conditions is a priority for many healthcare systems. Personal health records have been suggested to facilitate implementation of chronic care programs. However, patients' attitude towards personal health records (PHRs) can significantly affect the adoption rates and use of PHRs.

Objectives: to evaluate the attitude of patients with Type II diabetes towards using a PHR to manage their condition.

Methods: We used a cross-sectional exploratory pilot study. Fifty-four (54) patients used a PHR to monitor and record their blood glucose levels, diet, and activities for 30 days, and to communicate with their clinicians. At the end of the study, patients responded to a survey based on three constructs borrowed from different technology acceptance frameworks: relative advantage, job fit, and perceived usefulness. A multivariate predictive model was formed using partial least squaring technique (PLS) and the effect of each construct on the patients' attitude towards system use was evaluated. Patients also participated in a semi-structured interview.

Results: We found a significant positive correlation between job fit and attitude (JF $\rightarrow$ ATT $=$ $+0.318, p<0.01)$. There was no statistical evidence of any moderating or mediating effect of other main constructs or any of the confounding factors (i.e., age, gender, time after diagnosed) on attitude.

Conclusion: The attitude of patients towards using PHR in management of their diabetes was positive. Their attitude was mainly influenced by the extent to which the system helped them better perform activities and self-manage their condition.

\section{Correspondence to:}

Martin Ferguson-Pell,

Faculty of Rehabilitation medicine,

University of Alberta,

2-545 Edmonton Clinic Health Academy,

Edmonton, Alberta, Canada, T6G 1C9,

Telephone: 1-780-492-4383

Email: Martin.ferguson-pell@ualberta.ca
Appl Clin Inform 2016; 7: 573-586

http://dx.doi.org/10.4338/ACI-2015-12-RA-0180

received: January 6, 2016

accepted: April 11, 2016

published: June 22, 2016

Citation: Azad Khaneghah P, Miguel-Cruz A, Bentley P, Liu L, Stroulia E, Ferguson-Pell M. Users' attitudes towards personal health records: A cross-sectional pilot study Appl Clin Inform 2016; 7: 573-586

http://dx.doi.org/10.4338/ACl-2015-12-RA-0180 


\section{Background}

Web-based personal health records (PHR) are becoming increasingly popular in client-centered healthcare systems [1]. According to the Markle Foundation [2] a PHR is "an electronic application through which individuals can access, manage, and share their health information in a secure and confidential environment". The content of a PHR is usually controlled by the patient, and may or may not be tethered to a patient's electronic health records [1]. Use of PHRs has the potential to expand a patients' role in self-managed care [3]; in addition, PHRs can improve quality of care, reduce health care costs, and improve access to health information [4]. Kahn et al. suggested that an ideal PHR could facilitate productive interactions between patients and clinicians by providing a secure and reliable platform for communication and information exchange [5]. Further, PHRs have the potential to support preventive measures by way of patient reminders for screening tests [1].

Prevention and management of Type II diabetes is a priority for health care systems as the number of individuals with diabetes and the projected costs of care for this condition are increasing [6]. On the other hand, patients with Type II diabetes may benefit significantly from using a PHR. Contemporary diabetes management programs require active participation of patients in management of their condition through measuring their blood glucose levels and reporting this data to their care providers regularly [7]. PHRs have the potential to assist patients with all these tasks and provide a secure way to collect, store, and transfer health related data.

Several PHRs are available in Canada, some of which were developed by provincial health care systems and are available to residents free of charge. In province of Alberta, for example, "MyHealth.Alberta.ca" has recently been introduced. Private sector PHRs have also been developed and operate on a fee-for-service basis. However, little is known about patients' attitude and perceptions towards using PHRs in self-monitoring programs [8]. This knowledge is of interest to the following groups: (1) developers of PHRs, to help them improve their products and explore new markets; (2) health care providers, to increase their knowledge about the potential of using health information technology in chronic-disease management programs; and finally (3) patients with chronic conditions, who are interested in better management of their health condition.

\section{Objective}

The objective of our study was to evaluate the attitudes of patients with a chronic condition (Type II diabetes) towards using a PHR for the purpose of self-monitoring and diabetes management. Unlike other studies that have only used qualitative evaluation of individuals' perceptions about PHRs [9, 10], we used both quantitative and qualitative approaches to answer the following research questions:

1. What is the attitude of patients with Type II diabetes toward using a PHR?

2. What are the perceptions of patients with Type II diabetes toward using a PHR to self-monitor their blood glucose levels?

\section{Methods}

\subsection{Design}

We used a cross-sectional design, and collected data with a self-administered paper-based survey and a semi structured interview. From a theoretical perspective, we based our evaluation on the Theory of Reasoned Action and its expansion, the Theory of Planned Behaviour [11]. According to these theories, beliefs are determinants of an individuals' attitude. In turn, attitude, along with subjective norms, determine an individual's behaviour [11] (here, using a PHR). Attitude toward behaviour is defined as "an individual's positive or negative feelings (evaluative affect) about performing the target behaviour" [11]. While attitude refers to a person's favourable or unfavourable evaluation of a certain object, it is an individual's beliefs that represent what information he or she has about an 
object, or in this case, a system or platform such as the PHR. Therefore, beliefs link an object with its attributes that influence attitude.

For measures of belief, we used three constructs from different theories of usability and technology acceptance: perceived usefulness (PU) from Technology Acceptance Model [12], relative advantage (RA) from Rogers' Innovation Diffusion Theory [13], and job fit (JF) from Model of Personal Computer Utilization [14]. The first construct, "perceived usefulness", is a person's belief that using a system may improve his performance at a task [13]. The second one, "relative advantage", refers to one's belief that a device works better than a previous version of the same device [13]. Finally, "job fit" refers to how a system can improve the way a person does his job [13] that is self-monitoring blood glucose levels in our study.

\subsection{Description of the Telus Health Space PHR}

The PHR used was TELUS Heath Space personal health record (THS-PHR), developed based on the Microsoft Health Vault ${ }^{\mathrm{T}}$. This PHR provides a secure web-based portal, enabling patients to enter, store, manage, and share health information with selected caregivers. It also offers a secure messaging system that allows patients to communicate directly with caregivers. THS-PHR has the potential to be used in monitoring and self-management of chronic conditions such as cardiopulmonary diseases, mental health issues, diabetes, and obesity. It has different tabs for each condition, under which relevant data such as blood glucose levels, blood pressures, or body dimensions can be entered by patients. THS-PHR was not available to the residents of Alberta prior to this study, which minimized chances of prior exposure to the system that could potentially influence their attitude towards the PHR.

\subsection{Sample}

A non-probability convenience sampling method was used for this study. Participants were recruited from the Diabetes Management Clinic at Sherwood Park Primary Care Network (SP-PCN) in Alberta, Canada [15]. Patients were recruited based on the following inclusion criteria:

1. At least 40 years of age [16],

2. Diagnosed with Type II diabetes,

3. Living at home,

4. Willingness to measure their own blood-glucose levels using a glucose meter or have a designated care taker to do this, and

5. Access and familiarity with a personal computer and internet.

6. English-speaking

Individuals with vision impairment or inability to provide informed consent were not included. The minimum sample size required for this study was 40 subjects, enough to achieve a statistical power of 0.80 with a large effect size $\left(\mathrm{f}^{2}=0.35\right)$ [17].

\subsection{Procedures}

The case manager at diabetes management clinic of SP-PCN reviewed the list of patients with Type II diabetes and identified those who met the inclusion criteria for the study. She contacted each patient and explained the purpose of the study. The case manager then obtained verbal consent from patients who agreed to volunteer for the study. She then provided patients' contact information to the research team. A researcher (P.A.K) contacted and met with each patient at his or her home or at the SP-PCN office. During this meeting, the researcher provided complete information about the study, obtained written informed consent, and trained each patient to use the PHR.

Each patient was assigned a password-protected account on the THS-PHR. On the homepage, patients could view their most recent data entries and any messages from their clinicians. Patients were able to edit their profile information, password, account settings, and grant access to their clinicians to view their information. Patients could use secure online messages to communicate with their clinicians. Participating clinicians were also assigned a username and password to a secure 
dashboard that could connect to patients' PHR if patients consented. They could monitor patiententered data and use a secure messaging system to communicate with them. They were also able to download and print reports and graphs of patients' data for record keeping. Patients were requested to record and enter the blood glucose levels, date, and time of each reading in their PHR accounts as instructed by their clinician for 30 days. Technical support was available by phone to patients to solve any problems with their PHR account.

After 30 days, the researcher (P.A.K.) met with patients at the PCN office or at patients' home and provided them a quantitative survey to complete. The survey was designed by the research team using standard questions, based on constructs from three theoretical frameworks of usability and technology acceptance. Participants answered 13 questions ( $>$ Table 2): four questions on relative advantage (RA) from Rogers' Innovation Diffusion Theory, four questions on job fit (JF) from Model of Personal Computer Utilization, three questions on perceived usefulness (PU) from Technology Acceptance Model, and finally, two questions on attitude. Patients used a 5-point Likert scale, ranging from "1" (strongly disagree) to "5" (Strongly agree) to respond. Patients also specified their gender, age, time since diagnosed with diabetes, and if they used insulin to manage their blood glucose level. The items used in the questionnaire were adopted from a list of standard questions developed by Venkatesh et al. [13]. These questions have been validated and can be used as standard questions for evaluation of constructs that influence the attitude toward technology. The items were also reviewed by a panel of experts on the research team from different disciplines such as computer science and health care.

To evaluate the perception of patients about the PHR, all patients participated in a short, 30-minute semi-structured face-to-face interview immediately after completing the survey. The researcher used an interview guide which consisted of 15 open-ended questions (Appendix A). The goal of the interview was to collect more information about the positive and negative perceptions of participants about using THS-PHR to self-monitor their blood glucose level.

\subsection{Data analysis}

\subsubsection{Quantitative data}

In order to evaluate the attitude of patients with Type II diabetes towards using the THS-PHR, a multivariate model was developed using the partial least squaring (PLS) technique. Smart PLS V 3.1.6 statistics package was used to generate PLS path modeling [18]. The Validity and reliability of the PLS model were evaluated using the following criteria:

1. Reliability of each construct was evaluated using the Cronbach's alpha (CA>0.7) and Internal Composite Reliability (ICR> 0.708) [19].

2. Convergent validity of each set of items with respect to their associated construct was assessed by examining the factor loadings of the items, which should be greater than 0.7 , and the value of Average Variance Extracted (AVE), which should be greater than 0.5 [19].

3. Discriminant validity was evaluated by using the Fornell-Larcker criterion, based on which the square root of the AVE value for each construct should be greater than its highest correlation with any other constructs [19].

The PLS structural model was evaluated by means of paths coefficients $(\beta)$, the explained variance $\left(\mathrm{R}^{2}\right)$ and the effect size $\left(\mathrm{f}^{2}\right)$ for each path segment of the model. A hierarchical, multiple-regression method was used for the development of the model, in which all variables were entered in the model and deleted one by one until a combination was found with highest explained variance $\left(\mathrm{R}^{2}\right)$. The Bootstrapping re-sampling method was employed to verify the statistical significance of $(\beta)$ paths coefficients [19]. The level of statistical significance was set at $p<0.05$.

\subsubsection{Qualitative data}

To understand the patients' perceptions about THS-PHR, the interviews were digitally recorded and transcribed verbatim and then analyzed qualitatively using directed content analysis method. The research team developed a list of codes related to patients' perceptions through a deductive coding approach [20]. The top level categories for coding system were "perceived ease of use", "perceived impact on self-managed care", "Perceived quality of care", "user retention", and "suggested improve- 
ments". Two authors (P.A.K. and P.B.) used this classification scheme to code the data and summarized the results independently in separate tables. After that, they compared their findings and discussed the differences until consensus was achieved.

\section{Results}

\subsection{Participants' characteristics}

Fifty-four patients and nine clinicians participated in the study. The mean age of patients was 54 years (SD 7.5). The majority of patients were male and diagnosed with diabetes for less than 10 years ( Table 1). Overall, patients reported that the THS-PHR improved their involvement and interest in self-managing Type II diabetes. They perceived that using this technology would improve servicedelivery efficiency. Patients reported that they had confidence in the technology and as a result of using this technology they perceived that they did not need to visit their health care provider as frequently as before ( $>$ Table 2 ).

\subsection{Multivariate analysis: Patients' Attitude toward technology (PHR)}

Table 3 and $>$ Table 5 show the path model and the bootstrapping procedure ran with 5000 samples. The multivariate model in PLS ( Table 3 and $>$ Figure 1) shows that there was a statistically significant and positive correlation between job fit and attitude toward the use of the PHR (JF $\left.\rightarrow \mathrm{ATT}^{1}=+0.318, p<0.01\right)$; there was no statistical evidence to support that relative advantage has a positive influence on attitude toward the use of the PHR (RA $\rightarrow$ ATT $=+0.274, p<0.097$ ); and there was no statistical evidence to support the assertion that as age of participants increases the attitude toward the use of the PHR decreases (Age $\rightarrow$ ATT $=-0.121 p<0.255$ ). The effect of perceived usefulness on attitude was positive and significant. However, we eliminated this construct from the model because of its co-linearity with job fit.

\subsection{Model Validity and Reliability}

In general, the validity and reliability of the PLS model are good. The results of the construct correlations, internal composite reliability and Cronbach's alpha values, and average variance extracted from the reflective constructs showed that all item loadings were statistically significant at the 0.001 level and most of item loadings (80\%) were greater than 0.70 . Only two item loadings (9\%) were in the interval between 0.6 and 0.4 , indicating acceptable convergent validity at the indicator level [19]. All internal composite reliability values were greater than 0.70 , indicating acceptable reliability of the model. The square root of each average variance extracted (AVE) was greater than the related interconstruct correlations in the construct correlation matrix, indicating adequate discriminant validity for all reflective constructs (see $>$ Table 4 for more detail).

The Stone-Geisser's $Q^{2}$ values for attitude to use the THS-PHR was 0.167 (i.e., $Q^{2}>0$ ), indicating good predictive relevance of our model. The explained variance of the model was $R^{2}=0.324$, which appears to be strong for behavioral sciences research [17] ( $\$$ Table 3 for details). Finally, power analysis indicated that the power of the multivariate model was high (greater than 95\%), which represents a reasonable protection against Type II error [21].

1 The symbol " $\rightarrow$ " is the path between two variables, similar to the correlation or beta coefficient in a regular multivariate regression. The number $(+0.318)$ is the beta coefficient of the path; the p-value is the statistical significance of the correlation. 


\subsection{Qualitative Findings}

\subsubsection{Perceived ease of use.}

In general, patients reported that the PHR was easy to use and submitting the information online was more efficient and convenient than travelling to the clinicians' office:

"It was easy, very easy, it's very straightforward"; "It was easy, efficient, saved me time making an appointment and waiting for that appointment and getting to the appointment".

Many participants emphasized the significance of the initial face-to-face training that they received at the beginning of the study:

"It was very good, otherwise you wouldn't know where to go and what to do you did a good job of the training for sure"; "It was very useful I wouldn't have had a clue what I was doing if I did not receive any training".

\subsubsection{Perceived impact on self-managed care}

Patients either reported that there was no impact or a positive one. About one third of the participants said that the technology had not significantly impacted the way they managed their diabetes. These patients also mentioned that they were diagnosed for several years and believed that they were already successful at managing their diabetes. One patient for example said: "None, I guess as I say I didn't have any concerns, and it wasn't that I was newly diagnosed or that I needed a lot of support, so I think it really didn't impact very much". Another patient said: "Well, it was pretty wellmanaged before I did it, so it really didn't change anything".

On the other hand, patients who were newly diagnosed or for some reason were not successful at managing their blood glucose levels using the conventional methods said that using THS-PHR positively impacted their self-managed care: "It made me more aware that I should be taking my measurements more often". According to these patients, the impact was mostly because of the feedback they received from the visual presentation of blood glucose data: "With the chart and everything it was better than just putting down numbers because you could actually see if you were in your range and what you had to do to change it if it went out".

\subsubsection{Perceived quality of care}

About half of the participants stated that they perceived an increase in the level of support that they received while they were using THS-PHR. Most of these patients were the same who perceived a positive impact on self-managed care. They mentioned "facilitated communication" with their clinicians as the main reason for this:

"I got comments back, whereas typically I wouldn't see them for the month, so I guess it impacted the care a little bit. I guess it improved it"; "I get some feedback from the healthcare worker, that I probably would not have been looking for, so I guess that the impact [was] positive I would say"; "A positive impact because as I was saying earlier we were able to get feedback in a much shorter time and control my blood sugar much better than prior to the program".

Similarly, patients who did not perceive a positive impact on their self-managed care did not perceive a positive impact on quality of care either. However, none of the participants reported any negative impact on perceived quality of care as a consequence of using THS-PHR.

\subsubsection{User retention}

The majority of patients (90\%) said that they were willing to continue using the system. Among those who did not want to continue using THS-PHR, two patients said they were not comfortable with computers, and two other patients simply preferred a pen-and-paper method of recording data. One participant preferred to use Microsoft Excel spreadsheets: 
"I am more comfortable with the pen and paper method".

"I'm thinking probably at this stage no, I think it's pretty well under control, so at this stage I think they [clinicians] would just get bored with reading this on and on".

Although the majority expressed their willingness to continue with the program, only five participants agreed that they would be willing to pay an annual or monthly service fee to use THS-PHR: "Depends how much it was. If it was a very significant fee I don't think itd be worth using". The majority of the patients believed that the costs should be covered by the public health care system: "I think it should be picked up by the healthcare. It's hard to think of how much a day or how much a month it would be worth".

\subsubsection{Suggestion to improve THS-PHR and limitations}

Patients made a number of suggestions to improve the THS-PHR:

1. Reducing the number of steps needed to open the data entry page

2. Designing a mobile app for the PHR

3. Providing wireless connection between the glucose meter and the PHR

4. Being notified through e-mail or text message when their clinician leaves a message for them on the PHR.

On the other hand, several participants did not have any suggestions and considered the current system useful as it was: "Actually with what I used it worked really [well], I can't see anything on how it can be improved, it took the readings, graphed everything for me, no I thought it worked really well".

\section{Discussion}

According to our multivariate model, there was a positive correlation between the job fit and attitude towards using the THS-PHR. In other words, as the capabilities of the PHR system enhanced patients' job performance (i.e., self-management of medical condition) their attitude toward the PHR use was positive. This means that patients were more likely to use a PHR, if they perceived that the system could help them with the tasks of a chronic disease self-management program such as self-monitoring, recording the data, and communicating with clinicians. This finding was confirmed by the qualitative data from the interviews. The majority of patients ( 49 of 54) responded positively when they were asked if they were willing to continue using the system. In other words, the PHR "fits" with their "job" in their diabetes self-management program.

Our results indicated that age was not a determinant of the THS-PHR use. Other studies have reported mixed findings. For example, Logue and Effken [22] reported that age has a negative correlation with PHR adoption. On the other hand, Archer et al. [23] reported older adults as one of the age groups that have the potential for better adoption of PHRs. We believe that, to better explain the role of age in adoption of PHRs, we have to consider other confounding factors, computer literacy being one important factor. Perhaps the negative effect of age reported by some authors is because there were generally more computer savvy individuals among younger adults in their studies [24]. In our study, we controlled for this confounding factor by purposefully recruiting patients who were familiar with computer use. As a result, we found no correlation between age and attitude towards using the THS-PHR. In other words, if users have the skills necessary to use the system, their attitude would not be influenced by age.

The multivariate model also indicated that there was no significant correlation between the relative advantage and attitude towards using the THS-PHR. This means that although patients found the system useful and to fit their needs, they did not believe that the THS-PHR had considerable superiority compared to other methods of self-management. However, we propose a careful interpretation of this finding. The analysis of the patients' interviews revealed that patients who had recently been diagnosed and referred to the program found the system very useful. On the other hand, patients who were managing their condition successfully for a long time believed that they were able to perform their self-management tasks without using the THS-PHR. 
Another factor that might have influenced their perception about relative advantage is patients' expectations. According to patients' responses to the interview questions, those who were satisfied with options currently available in the THS-PHR such as data repository, data graphs, and instant messaging, perceived THS-PHR as useful to help them control their blood glucose levels. On the other hand, patients who expected to see more features in the system may have perceived that THSPHR was not relatively more useful than the conventional methods. These patients expressed their expectations under the category of "suggestions to improve the system". However, we suggest that although the findings did not show a relative advantage, it did not provide evidence that using the THS-PHR negatively impacted patients' ability to self-manage their condition either. We suggest conducting studies with larger samples and for longer durations to investigate any negative or positive effects.

An interesting observation was the difference between the perceived impact on care between patients who were new to self-managed care and those who were engaged in the self-managed program for several years. Generally, the inexperienced patients were more positive about their use experience and reported a positive impact on their care. On the other hand, patients with more selfmanaged care experience said that the system did not impact the way they managed their condition. The positive impact perceived by less experienced patients might have been a secondary effect of beginning a self-managed care program and not necessarily the impact of the system. It could also be associated with the fact that inexperienced patients were generally younger and had a more positive attitude towards using new technologies. At this point we do not have enough evidence to conclude that PHR was perceived relatively more advantageous compared to the traditional methods. Any existing relative advantage is also not large enough to convince patients with more experience in self-managed care to change their habits or routines and adopt THS-PHR. This is especially true if it requires them to pay additional costs in the form of service fees that are not covered by the public health care system.

Previous studies have mentioned perceived usefulness as one of the main determinants of users' attitude [12, 25]. Our results also indicated a significant and positive correlation between these two factors. However, we eliminated perceived usefulness from the final PLS model because of the colinearity between this construct and job fit. This likely occurred because job fit construct "captured" all the variance explained by perceived usefulness [13]. In other words, the questions pertaining to perceived usefulness and job fit measured the same "beliefs" among patients, or at least patients perceived them as measuring the same beliefs.

\subsection{Limitations of the study}

We recruited a small and non-random sample size that restricts the generalizability of the results. We only recruited patients with Type II diabetes, within a certain age group, who lived in a specific city. This sampling limits the generalizability of the findings to patients with other conditions and from other socioeconomic backgrounds. For convenience we limited our sample to English speakers only. Moreover, these results only apply to users who have basic familiarity with computer and internet use. We kept the length of the survey short to minimize the burden on the participants. For this reason we only focused on effect of attitude on use behaviour and postponed evaluation of other determinants of use behaviour to future studies. Finally, clinicians' perceptions were not included in this study. This was because very few clinicians (nine) volunteered to monitor their patients using the PHR. Because of this small sample size it was not possible to use the PLS model to explain clinicians' attitude about the PHR. Since successful implementation of a PHR depends on acceptance of this technology by both clinicians and patients, further studies are suggested to evaluate clinicians' attitudes and perceptions.

\subsection{Future Research}

Future studies with larger sample sizes that consist of patients with different chronic conditions are recommended as PHRs are meant to be used by patients to self-manage multiple conditions. Development of a standardized questionnaire according to a more comprehensive usability framework, such as the unified theory of acceptance and use of technology (UTAUT) [13], is advised. Such a 
questionnaire would make it possible to evaluate multiple factors that influence patients' use behaviour towards PHRs.

\section{Conclusion}

According to this study the attitude of patients with Type II diabetes towards PHRs is positive. PHRs can be more useful to patients who are either new to self-managed care or have difficulties with adopting the traditional methods (i.e., pencil and paper log books, regular visit to the clinic, etc.). On the other hand, PHRs may not have any relative advantage compared to other traditional methods of self-managed care for experienced patients or those who are already comfortable with the traditional methods. Further studies are needed to evaluate other factors that may influence patients' use behaviour towards PHRs.

\section{Clinical relevance Statement}

The findings of this study are of interest to developers of PHRs to help them improve their products and explore new markets. On the other hand, health care providers can use these findings to increase their knowledge about the potential uses of PHRs in chronic-disease management programs.

\section{Declaration of conflict of interest}

None of the investigators derived personal benefit linked to the outcomes of the study. Two of the investigators' (P.A.K. and P.B.) research salaries were funded by the collaboration grant from TELUS Healthcare. Additional Funding was received from MITACS accelerate grant in the form of MITACS internship grant (received by P.A.K.) and Post-Doctoral Fellowship grant (received by A.M.C.).

\section{Protection of Human and Animal Subjects}

The study was performed in compliance with the World Medical Association Declaration of Helsinki on Ethical Principles for Medical Research Involving Human Subjects. All procedures involving human participants were approved by the University of Alberta Research Ethics Board, under protocol number Pro00021480.

\section{Acknowledgement}

We wish to thank all the patients and clinicians who participated in the study and the staff of the Sherwood Park Primary Care Network. This project was funded in part by a research collaboration grant with TELUS Healthcare. Additional funding was provided by the MITACS accelerate program. 


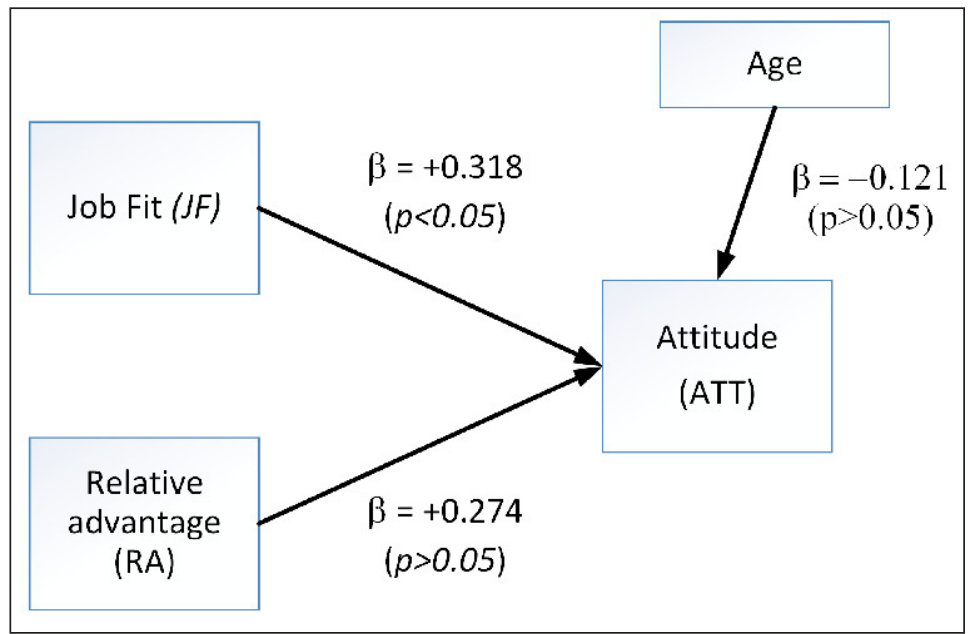

Fig. 1

The Measurement Model 


\begin{tabular}{l|l}
$\begin{array}{l}\text { Gender } \mathbf{n}(\%) \\
\text { Female } \\
\text { Male }\end{array}$ & $22(40.7)$ \\
$32(59.3)$ \\
\hline $\begin{array}{l}\text { Age (years) mean } \pm \text { SD } \\
\text { Years since diagnosis mean } \pm \text { SD }\end{array}$ & $8 \pm \pm 7.53$ \\
\hline Using Insulin $\mathbf{n}(\%)$ & $22(40.7)$ \\
\hline
\end{tabular}

Table 1 Demographics

Table 2 Patient responses to questionnaire regarding use of THS-PHR.

\begin{tabular}{|c|c|c|c|}
\hline \multirow[t]{2}{*}{ Question \# } & \multirow[t]{2}{*}{ Question } & \multicolumn{2}{|c|}{$\begin{array}{l}\text { Patients' response statistics } \\
(n=54)\end{array}$} \\
\hline & & Mean \pm SD & Median \\
\hline \multicolumn{4}{|c|}{ Attitude Construct } \\
\hline Q1 & $\begin{array}{l}\text { THS has made me more interested/involved in self-ma- } \\
\text { naging my medical condition }\end{array}$ & $4.26 \pm 0.89$ & 4 \\
\hline Q2 & I have confidence in the THS technology & $4.37 \pm 0.62$ & 4 \\
\hline \multicolumn{4}{|c|}{ Relative Advantage Construct } \\
\hline Q3 & $\begin{array}{l}\text { THS could be more time efficient than having my care } \\
\text { givers come to house to take my blood glucose readings }\end{array}$ & $4.81 \pm 1.12$ & 5 \\
\hline Q4 & $\begin{array}{l}\text { THS could provide for a more efficient process overall } \\
\text { than having a care giver come to my home }\end{array}$ & $4.65 \pm 1.03$ & 5 \\
\hline Q5 & $\begin{array}{l}\text { THS could improve the overall efficiency of health care } \\
\text { staff resource use }\end{array}$ & $4.44 \pm 0.60$ & 4.5 \\
\hline Q6 & $\begin{array}{l}\text { THS could save health care staff time over the traditional } \\
\text { home visit }\end{array}$ & $4.7 \pm 0.63$ & 5 \\
\hline \multicolumn{4}{|c|}{ Job Fit Construct } \\
\hline Q7 & $\begin{array}{l}\text { THS could increase health care provider's access to my } \\
\text { health information }\end{array}$ & $4.41 \pm 0.57$ & 4 \\
\hline Q8 & $\begin{array}{l}\text { THS could increase the efficiency of how my health infor- } \\
\text { mation is communicated with other members of the } \\
\text { health care team }\end{array}$ & $4.46 \pm 0.54$ & 4 \\
\hline Q9 & $\begin{array}{l}\text { THS could reduce the time spent by healthcare workers to } \\
\text { access my health information }\end{array}$ & $4.46 \pm 0.67$ & 4 \\
\hline Q10 & $\begin{array}{l}\text { THS could allow health care staffs to more effectively } \\
\text { communicate my health information with one another }\end{array}$ & $4.63 \pm 0.53$ & 5 \\
\hline \multicolumn{4}{|c|}{ Perceived Usefulness Construct } \\
\hline Q11 & THS could decrease the number of required home visits & $4.65 \pm 0.68$ & 5 \\
\hline Q12 & $\begin{array}{l}\text { THS could decrease time spent delivering care to the indi- } \\
\text { viduals in an emergency situation }\end{array}$ & $4.37 \pm 0.65$ & 4 \\
\hline Q13 & THS Could improve the quality of patient care & $4.41 \pm 0.57$ & 4 \\
\hline
\end{tabular}


Table 3 Structural Model Table

\begin{tabular}{|l|l|l|l|l|l|l|}
\hline Path $^{\text {a }}$ & Path Coefficient $\boldsymbol{\beta}$ & $95 \% \mathrm{Cl}$ & t-value & $\mathbf{f}^{2 \mathbf{b}}$ & $\mathbf{Q}^{2 \mathrm{c}}$ & $\mathbf{R}^{2 \mathrm{~d}}$ \\
\hline $\mathrm{RA} \rightarrow$ ATT & +0.274 & $(-0.046,0.558)$ & 1.79 & 0.048 & & \\
\hline $\mathrm{JF} \rightarrow$ ATT & +0.318 & $(0.057,0.671)$ & $2.09 *$ & 0.064 & 0.167 & 0.324 \\
\hline $\mathrm{AGE} \rightarrow$ ATT & -0.121 & $(-0.316,0.099)$ & 1.13 & 0.022 & & \\
\hline
\end{tabular}

a The path between the constructs: Relative Advantage (RA), Job Fit (JF), and Attitude (ATT).

${ }^{b} f^{2}$ : Effect Size

' $Q^{2}$ : Stone Geisser indicator

${ }^{d} R^{2}$ : Squared multiple correlations, representing the explained variance by the model

${ }^{*} p \leq 0.05$

Table 4 Construct Correlations

\begin{tabular}{|c|c|c|c|c|c|c|c|c|c|}
\hline Construct $^{\mathrm{a}}$ & Mean & $\pm S D^{b}$ & $\mathrm{CA}^{\mathrm{C}}$ & $I \mathrm{CR}^{\mathrm{d}}$ & AVE $^{e}$ & Age & ATT & JF & RA \\
\hline Age & 62.46 & 7.53 & SIC & SIC & SIC & SICf & & & \\
\hline ATT & 4.31 & 0.77 & 0.50 & 0.800 & 0.666 & -0.123 & $0.816^{*}$ & & \\
\hline JF & 4.49 & 0.58 & 0.836 & 0.887 & 0.668 & -0.007 & $0.526^{9}$ & $0.817^{*}$ & \\
\hline RA & 4.51 & 0.63 & 0.710 & 0.872 & 0.773 & 0.004 & $0.514^{g}$ & $0.756^{g}$ & $0.879^{*}$ \\
\hline
\end{tabular}

${ }^{a}$ Constructs: Attitude (ATT), Job Fit (JF), Relative Advantage (RA), and age of patients.

b SD: Standard deviation

c CA: Cronbach alpha

${ }^{d}$ ICR: Internal composite reliability

e AVE: Average Variance Extracted

${ }^{f} \mathrm{SIC}$ : Single item construct

${ }^{g}$ Latent variable correlations (Inter-construct correlations)

* The bold values are the square root of AVE. To meet the Fornell-Larcker criterion for discriminant validity, these values should be greater than latent variable correlations.

Table 5 Measurement Model

\begin{tabular}{|c|c|c|c|c|}
\hline Item or Question & Item loading & T-stat & ICR $^{\mathrm{a}}$ & AVE $^{b}$ \\
\hline \multicolumn{5}{|c|}{ Relative advantage (RA) } \\
\hline Q3 - RA & $<0.4$ & $N A^{c}$ & \multirow{4}{*}{0.872} & \multirow{4}{*}{0.773} \\
\hline Q4 - RA & $<0.4$ & $N A^{c}$ & & \\
\hline Q5 - RA & 0.901 & $23.250^{* *}$ & & \\
\hline Q6 - RA & 0.856 & $14.536^{* *}$ & & \\
\hline \multicolumn{5}{|l|}{ Job Fit (JF) } \\
\hline Q7-JF & 0.906 & $22.476^{* *}$ & \multirow{4}{*}{0.887} & \multirow{4}{*}{0.668} \\
\hline Q8-JF & 0.923 & $25.416^{* *}$ & & \\
\hline Q9-JF & 0.607 & $2.768^{* *}$ & & \\
\hline Q10-JF & 0.794 & $14.386^{* *}$ & & \\
\hline \multicolumn{5}{|l|}{ Attitude (ATT) } \\
\hline Q1-ATT & 0.818 & $8.464^{* *}$ & \multirow[b]{2}{*}{0.800} & \multirow[b]{2}{*}{0.666} \\
\hline Q2-ATT & 0.814 & $8.703^{* *}$ & & \\
\hline
\end{tabular}

${ }^{* *}: \mathrm{p}<0.01$

a ICR: Internal composite reliability

${ }^{\mathrm{b}}$ AVE: Average variance extracted

'NA: Not applicable, items with loading less than 0.4 were not included in the model. 


\section{Appendix A}

\section{Interview guiding questions}

1. Was it easy or difficult for you to take your own blood glucose levels?

2. Was it easy or difficult for you to enter and submit this information to the TELUS Health Space using your computer? What part of the procedure made it easy and what parts made it difficult?

3. What are the benefits and challenges (pros and cons) of you taking your own readings and submitting the results using your computer?

4. At the beginning of the study, you received training on using this technology. Comment on the usefulness of this training.

5. Do you have any suggestions on how to improve the training regarding the THS-PHR?

6. Did you find any limitations in using the PHR?

7. What impact has the technology had on your ability to manage your diabetes?

8. What was the impact of using your computer to submit your blood glucose levels to your health care provider?

9. Did you use the messaging system?

10.Compared to the other means of communication (telephone, fax, etc.) what was it like to use the messaging?

11.Did using messaging system affect your ability to manage your diabetes?

12.What was the impact of this technology on the quality of care you received?

13.Did this technology change the level of support you received from Sherwood Park PCN clinicians?

14.Would you continue using this technology as a way to share your blood glucose results and communicate with your health care provider?

15.Do you have any suggestions to improve this technology? 


\section{References}

1. Ant Ozok A, Wu H, Garrido M, Pronovost PJ, Gurses AP. Usability and perceived usefulness of Personal Health Records for preventive health care: a case study focusing on patients' and primary care providers' perspectives. Appl Ergon 2014; 45(3): 613-628.

2. Markle Foundation. Connecting Americans to their Health Care Final Report. 2004.

3. Tang PC, Ash JS, Bates DW, Overhage JM, Sands DZ. Personal health records: definitions, benefits, and strategies for overcoming barriers to adoption. Journal of the American Medical Informatics Association: JAMIA 2006; 13(2): 121-126.

4. Logue MD, Effken JA. An exploratory study of the personal health records adoption model in the older adult with chronic illness. Informatics in primary care 2012; 20(3): 151-169.

5. Kahn JS, Aulakh V, Bosworth A. What it takes: characteristics of the ideal personal health record. Health affairs (Project Hope) 2009; 28(2): 369-376.

6. Canadian Diabetes Association. The cost of diabetes in Alberta. 2009 [cited 2015 July,07]; Available from: http://www.diabetes.ca/documents/get-involved/diabetes-in-alberta.pdf.

7. Logue MD, Effken JA. Modeling factors that influence personal health records adoption. Computers, informatics, nursing: CIN 2012; 30(7): 354-362.

8. Angst CM, Agarwal R. Adoption of electronic health records in the presence of privacy concerns: the elaboration likelihood model and individual persuasion. MIS Quarterly 2009; 33(2): 339-370.

9. Andrews L, Gajanayake R, Sahama T. The Australian general public's perceptions of having a personally controlled electronic health record (PCEHR). Int J Med Inform 2014; 83(12): 889-900.

10. Butler JM, Carter M, Hayden C, Gibson B, Weir C, Snow L, Morales J, Smith A, Bateman K, Gundlapalli $\mathrm{AV}$, Samore M. Understanding adoption of a personal health record in rural health care clinics: revealing barriers and facilitators of adoption including attributions about potential patient portal users and self-reported characteristics of early adopting users. AMIA Annu Symp Proc 2013; 16: 152-161.

11. Fishbein M, Ajzen I. Belief, Attitude, Intention and Behavior: An Introductionto Theory and Research. MA: Addison-Wesle; 1975.

12.Davis FD. Perceived Usefulness, Perceived Ease of Use, and User Acceptance of Information Technology. MIS Quarterly 1989; 13(3): 319-340.

13. Venkatesh V, Morris GM, Davis GB, Davis DF. User Acceptance of Information Technology: Toward a Unified View. MIS Quarterly 2003; 27(3): 425-478.

14. Thompson RL, Higgins CA, Howell JM. Personal Computing: Toward a Conceptual Model of Utilization. MIS Quarterly 1991; 15(1): 125-143.

15. Teddlie C, Yu F. Mixed Methods Sampling: A Typology with Examples. Journal of Mixed Methods Research 2007; 1(1): 77-100.

16. Standards of Medical Care in Diabetes - 2012. Diabetes Care 2012; 35(Suppl. 1): S11-S63.

17. Chin W. The partial least squares approach to structural equation. In: GA M, editor. Modern methods for business research. Mahwah (NJ): Taylor \& Francis; 1998; 295-336.

18. Ringle CM, Wende, Sven, \& Becker, Jan-Michael. Smartpls 3. Hamburg: SmartPLS; 2014 [cited 2015 July 07]; Available from: http://www.smartpls.com.

19. Hair FJ HM, Ringle MCh, Sarstedt M. A primer on partial least sqares structural equation modeling (PLSSEM). Thousand Oaks (CA): SAGE; 2014.

20. Miles MB, Huberman AM, Saldaña J. Qualitative data analysis : a methods sourcebook: Thousand Oaks, Califorinia : SAGE Publications, Inc., Edition 3.; 2014.

21.Portney LG, Watkins MP. Foundations of Clinical Research: Applications to practice. Second ed. New Jersy Prince Hall 2000.

22.Logue MD, Effken JA. Validating the personal health records adoption model using a modified e-Delphi. Journal of advanced nursing 2013; 69(3): 685-696.

23. Archer N, Fevrier-Thomas U, Lokker C, McKibbon KA, Straus SE. Personal health records: a scoping review. Journal of the American Medical Informatics Association: JAMIA 2011; 18(4): 515-522.

24. Bickmore TW, Caruso L, Clough-Gorr K. Acceptance and usability of a relational agent interface by urban older adults. CHI '05 Extended Abstracts on Human Factors in Computing Systems; Portland, OR, USA. 1056879: ACM; 2005; 1212-1215.

25. Ajzen I. The theory of planned behavior. Organizational Behavior and Human Decision Processes 1991; 50(2): 179-211. 